\title{
Microbial Examination for Spoil Fruits and Vegetables and its Isolation, Identification, and Antimicrobial Sensitivity Pattern
}

\author{
P.K. Khatri ${ }^{1}$ and Sonali Sharma ${ }^{2 *}$ \\ ${ }^{1}$ Department of Microbiology, Dr. S.N. Medical College, Jodhpur, India \\ ${ }^{2}$ Lachoo Memorial College of Science and Technology, Sector A, \\ Shastri Nagar, Jodhpur, India \\ *Corresponding author
}

\section{Keywords \\ Fruits and Vegetables, Antimicrobial sensitivity pattern, Fungal and bacterial isolated \\ Article Info \\ Accepted: \\ 20 November 2018 \\ Available Online: \\ 10 December 2018}

\section{A B S T R A C T}

Fresh vegetables is a good source of various components of food that enhances a healthy living, but evidence shows that they promote the growth of microbes which also deteriorate the food and subsequently causes adverse effect on the health of consumers. Microbial investigation was conducted on different spoil vegetables and furits samples; collected from three different locations in jodhpur. The bacterial count ranged from carrot pineapple samples while the fungal count ranged from Cairca papaya and potato samples. Eight bacteria belonging to different genera, namely: Staphylococcus aureus, Bacillus sp, Escherichia coli, Pseudomonas aeruginosa, Enterobacter aerogenes, Serratia marcescens, Salmonella sp and Citrobacter sp were identified while six fungi, namely: Aspergillus niger, Thysanophoralongspora sp, Penicilum notatum, Neurospora crassa, Aspergillus fumigatus and Trichoderma $s p$ were also identified and isolated. Ciprofloxacin and augmentin exerted a pronounced inhibitory effect on all the bacterial isolates while nystatin and mycoten also inhibited all the fungal isolates with considerable zones of inhibition. All fungal isolates were resistant to griseofulvin with ketoconazole showing the lowest inhibitory zone $(2.0 \mathrm{~mm})$ on Aspergillus niger. Therefore, consumer $\mathrm{s}$ consciousness on the type and load of pathogens associated with vegetables and antibiotics of choice as a therapeutic measure against the infection caused by the implicated microorganisms needs to be re-awakened

\section{Introduction}

Fruits are known to have commercial and nutritional importance. They play a vital role in human nutrition by supplying some necessary nutritional substances such as vitamins and essential minerals in human daily diet that can help to keep a good and normal health. Fruits are widely consumed. One of the factors that imparts negatively on the economic value of fruits is that they have a short shelf-life. This is as a result of many factors, prominent among which is the activity of pathogens. It has been reported. Fruits and vegetables are exposed to contamination by microbes through contact with soil, dust and water and by handling at harvest or during postharvest processing. This makes them to harbour a wide range of microorganisms including plant and human pathogens. 
Differences in microbial profiles of diverse fruits and vegetables result could be due to varying factors including resident microflora in the soil, application of non-resident microflora through animal manures, sewage or irrigation water, transportation and handling by individual retailer (Ewekye, 2013).

Pineapple (Ananas comosus) is ranked the third most important tropical fruit in the world. Sixth on the list of world pineapple producers with about 800,000 tones produced per annum. Ananas comosus. is a rich source of Vitamin $\mathrm{C}$ as well as other vitamins and fibre. The fruit is also used as a raw material in confectionery industries. It also has various medicinal values (Amoa, et al., 2011).

Potato (Solanum tuberosum) is a staple crop in 130 countries worldwide, ranking fourth in production. The tuber is the most important part of the I potato plant and it is an excellent source of carbohydrates, protein and vitamins In Nigeria, $S$. tuberosum is responsible for more than half of the total carbohydrate requirements of the populace in areas where it is grown and consumed as a staple food (Omafuvbe and Enyioha, 2011).

Pawpaw (Carica papaya), is a major fruit crop cultivated all over the world Papaya fruit has high nutritive and medicinal value. The enzyme, papain, obtained from $C$. papaya is used as meat tenderizer, in manufacturing of chewing gum, in cosmetics (for shampoos and face lifting operation), and pharmaceutical industries (Snowdon, 1990).

Carrot (Daucus carota)It is a root vegetable usually orange in colour, though purple, red, white and a yellow variety exists. It has a crisp texture when fresh. The most commonly eaten part of carrot is the tap root. The leaves are not ingested in most of the cultures because it is mildly toxic but it is edible $D$. carota is very rich in vitamin $\mathrm{C}$ as well as carotene Despite all the benefits derived from carrots, a large percentage is lost annually to post harvest deterioration caused by pathogens (Jeanelle Boyer, 2004).

Apples (Muias domestica) are often eaten raw, but can also be found in many foods (especially desserts) and drinks. Apples can be canned or juiced; they are milled to produce apple cider (non-alcoholic, sweet cider) and filtered for apple juice. The juice can be fermented to make cider (alcoholic, hard cider), ciderkin, and vinegar. Health benefits of apple consumption are numerous because of the phytochemicals produced by such apple.

Banana (Musa paradisiaca L.), fruit is one of the most important commercial fruit and vegetable crops grown all over the world in the tropical and subtropical areas. It is the second largest fruit crop, and is indigenous to indo-Malayan region. Cultivation of edible bananas is believed to have been started in this region in prehistoric times. It is possibly the world's oldest cultivated crop. It can be grown round the year and it is widely adopted in India. Apart from this, it is considered as potential 'Dollar earning crop'.

Sapodilla tree (Manilkara zapota is native to tropical. The fruit production is mainly consumed locally. However, this fruit could be exported either in fresh or processed form, due to its sweet taste and unique aroma, highly appreciated by consumers. Sapodilla fruits are climacteric its ripening is rapid and is characterized by a significant increase in respiration and ethylene production, which makes this fruit highly perishable, and consequently very difficult to preserve and commercialize. The fruits ripen between 3 to 7 days after harvesting at $25^{\circ} \mathrm{C}$ and although it can be stored under refrigeration $\left(15^{\circ} \mathrm{C}\right)$ the use of low temperatures are restricted as it can cause a physiological dysfunction referred to as "chilling injury" which leads to deterioration and loss of quality. 
Tomato is an important vegetable grown for its edible fruit belonging to the genus Lycopersicon, being Lycopersicon esculentum. Lycopersicon Tomato (Lycopersicon esculentum Mill.) is the second most important vegetable worldwide, in terms of the amount of vitamins and minerals it contributes to the diet consumers are not satisfied with the quality of tomato is one of the most perishable vegetable. It is highly esteemed as a source of vitamins A and C, and some essential minerals Tomatoes are a good source of protein, but most of it is in the seeds. Tomato juice contain 19 amino acids principally glutamic acid. They are also a significant source of vitamin A.

Grapes (Vitis vinifera L.) are a well perishable commodity and their market life is a function of time and temperature, with the degree of deterioration related directly to the duration of exposure to higher temperatures. They are non-climacteric fruits which are meant for consumption as fresh with washing. Quality of table grapes is usually considered as a combination of appearance and flavor during shelf-life.

Pomegranate (Punica granatum L.) is one of the oldest known edible fruits and has been associated with several ancient cultures of the world. Its commercial cultivation started in many countries, especially in tropical and subtropical dry regions of the northern hemisphere. Its commercial potential and economic impact is enormous considering the different ways in which the fruit may be utilized (Morton, 1987).

The fresh fruit and juice market has grown steadily worldwide and has especially boomed in the US in recent years due to its increased consumer awareness of the potential health benefits (Seeram et al., 2006). Other commercial pomegranate products include jams, jellies, isolated arils and wines.
A visit to most markets revealed that between $15 \%$ and $40 \%$ of fruitdisplayed for sale showed symptoms of microbial infection and were sold at lower prices and were usually preferred by low income earners reported that Aspergillus niger, Aspergillus flavus, Rhizopus nigra, Curvalaria lanata, Rhizopus oryzae, Fusarium eqiuseti and Fusarium moniliforme were responsible for post harvest losses of pawpaw in south western Nigeria have also reported Penicillium digitatum and Fusarium oxysporium on pawpaw. Different fungal species have been reported to be associated with the post harvested deterioration of these fruits and vegetables in different locations. This study was carried out to investigate and document the fungi responsible for the spoilage of some fruits and vegetables.

This study was under taken "microbial examination for spoil fruits and vegetables and its isolation, identification, and anti microbial sensitivity pattern

\section{Materials and Methods}

\section{Methods}

During period of 15.02.2016 to 15.05.2016 the study was conducted in the department of Microbiology Dr. S.N. Medical College, Jodhpur. The study include 10 and more samples collecting from Jodhpur Market and Microbial isolation and its sensitivity test was performed for all culture by diffusion method. Out of 10 and 1 fourth day repeated Sample from various fruits and vegetables sample in the sample GNB species found in 7 sample and 2 Candida species and 1 Mucor and 1 Rhizopus found out of 11 sample 07 were GNB and 02 Candida species and other are Rhizopus and Mucor. In study group we found Gram Negative Bacilli (6/10) in spoil fruits and vegetables followed by E. coli species $(2 / 10)$ and Klebsiella species (4/10) and Pseudomonas species (1/10) and Candida 
species found in spoil fruits and vegetables (2/10) and Rhizopus (1/10) and Mucor (1/10) found in spoil fruits and vegetables.

\section{Sample}

The study is carried out by taking 10 samples of spoil fruits and vegetables.

\section{Selection of fruits and vegetables collection}

All the Spoil fruits and vegetables sample are were collected in Jodhpur market.

\section{Collection}

All spoil fruits and vegetables were inspected for Rotted areas and were stored in clean polyethylene bags.

\section{Procedure and processing}

On first day-

The samples were first surface sterilized by washing under distilled water. A flamed surgical blade was used to cut partly spoil portion of the sample, the cut portions were then surface sterilized using $70 \%$ alcohol and put into BHI medium.

The test tubes were incubated at $37^{\circ} \mathrm{C}$ over night.

On second day-

\section{Inoculation and incubation}

We check turbidity of BHI medium. We do streak on those medium Nutrient Agar (NA), Potato Dextrose Agar (PDA), Sabouraud Dextrose Agar (SDA), Blood Agar, MacConkey medium plates with a sterilized wire loop and then incubator for 24 hours at $37^{\circ} \mathrm{C}$. On third day-
We observed Bacterial and fungal growth on streak plates.

\section{Fungal colonies}

For bacterial identification, smears were prepared from colonies grown on streak culture plates. With the aid of a sterilized inoculating needle, a small portion of bacterial colony was transferred into the glass slide and teased properly with two sterilized inoculating needles colony was smears were air-dried, heat fixed and stained by Gram's technique helps to group the bacterial pathogen into Gram's positive or Gram's negative by the ability of bacterial cells to retain primary stain.

\section{Antibiotic and anti fungal sensitivity test}

Antibiotic and anti fungal sensitivity test Used was Kirby Bauer method (Baure et al., 1966). The medium used in this is Muller Hinton agar for bacterial and for fungal Muller Hinton agar + methylene blue + dextrose agar. It is a type of disc diffusion method.

It is the most used antibiotic/antifungal susceptibility test in determining what treatment of antibiotic/antifungal should be used when treating an infection. This method relies on the inhibition of bacterial growth measured under standard condition. For this test, culture medium specifically the Muller Hinton agar is uniformly and aseptically inoculated with the test organism and then antibiotic disc is placed on the medium. The organism will grow on the agar plate while the antibiotic, there will be no growth around the disc containing the $\mathrm{Ab}$. Thus a "Thus a "Zone of inhibition" can be observed and measured to determine the susceptibility to an antibiotic for that particular organism. The measurement is compared to the criteria set by NCCLS. Based on it, the organism can be classified as 
being Resistance (R), Intermediate (I) or Susceptible (S) (Table 1 and 2).

\section{Results and Discussion}

The present study was conducted in the department of Microbiology Dr. S.N. Medical College, Jodhpur. The study include 10 and more samples collecting from Jodhpur Market.

The aim of present study was to find out eating spoil fruits and vegetables infection and disease. The comparison of isolated GNB and Candida species from sample and Rhizopus and Mucor and their antibiotic/antifungal sensitivity pattern to different antibiotic and antifungal drugs as well as the comparison of efficacy of conventional GNB, Candida Species, and Rhizopus and Mucor found of the different species.

Out of 10 and 1 fourth day repeated Sample from various fruits and vegetables sample in the sample GNB species found in 7 sample and 2 Candida species and 1 Mucor and 1 Rhizopus found out of 11 sample 07 (63.63\%) were GNB and 02 (18.18\%) Candida species and other are $9.09 \%$ Rhizopus and Mucor.

In study group we found Gram Negative Bacilli (6/10) in spoil fruits and vegetables followed by E. coli species (2/10) and Klebsiella species (4/10) and Pseudomonas species (1/10) and Candida species found in spoil fruits and vegetables (2/10) and Rhizopus (1/10) and Mucor (1/10) found in spoil fruits and vegetables.

In Gram Negative Bacillus, Imipenem 100\% sensitive and Piperacillin 62.5\% sensitive Ceftriaxone and Amikacin is partially sensitive Amoxycillin and Ampicillin is not more sensitive.

In Candida species Rhizopus and Mucors, Clotrimazole is $100 \%$ Sensitive and Nystatin, Ketoconazole and Fluconazole is 50\% Sensitive and Miconazole and Itraconazole is partially sensitive (Fig. 1-3 and Table 3 and $5)$.

Table.1 For gram negative bacteria

\begin{tabular}{|l|l|c|}
\hline \multicolumn{1}{|c|}{ Anti-Microbial Agent } & \multicolumn{1}{c|}{ Code } & Disc Potency (mcg) \\
\hline Amikacin & AK & $30 \mathrm{mcg}$ \\
\hline Amoxycillin & AMX & $10 \mathrm{mcg}$ \\
\hline Piperacillin & PI & $100 \mathrm{mcg}$ \\
\hline Ceftriaxone & CTR & $30 \mathrm{mcg}$ \\
\hline Ampicillin & AMP & $10 \mathrm{mcg}$ \\
\hline Imipenem & IMP & $10 \mathrm{mcg}$ \\
\hline
\end{tabular}

Table.2 For fungal Candida spices, Rhizopus and Mucor

\begin{tabular}{|l|l|l|}
\hline \multicolumn{1}{|c|}{ Anti-Fungal Agent } & \multicolumn{1}{c|}{ Code } & \multicolumn{1}{c|}{ Disc Potency $(\mathrm{mcg})$} \\
\hline Nystatin & NS & $50 \mathrm{mcg}$ \\
\hline Clotrimazole & CC & $10 \mathrm{mcg}$ \\
\hline Itraconazole & IT & $10 \mathrm{mcg}$ \\
\hline Ketoconazole & KT & $10 \mathrm{mcg}$ \\
\hline Miconazole & MIC & $50 \mathrm{mcg}$ \\
\hline Fluconazole & FLC & $25 \mathrm{mcg}$ \\
\hline
\end{tabular}




\section{Spoil fruits and vegetables sample}

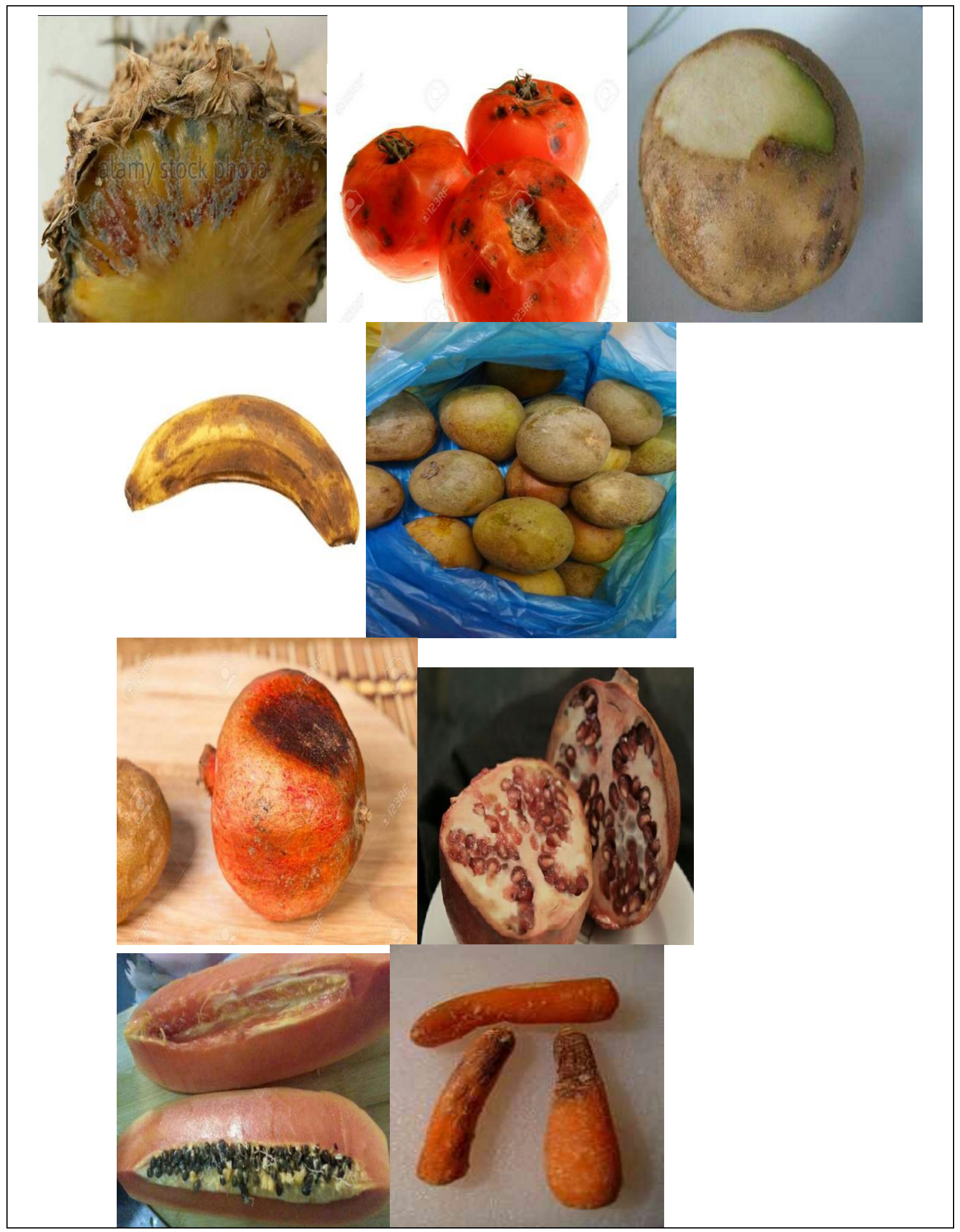

Fig.1 Sample in brain heart infusion broth 


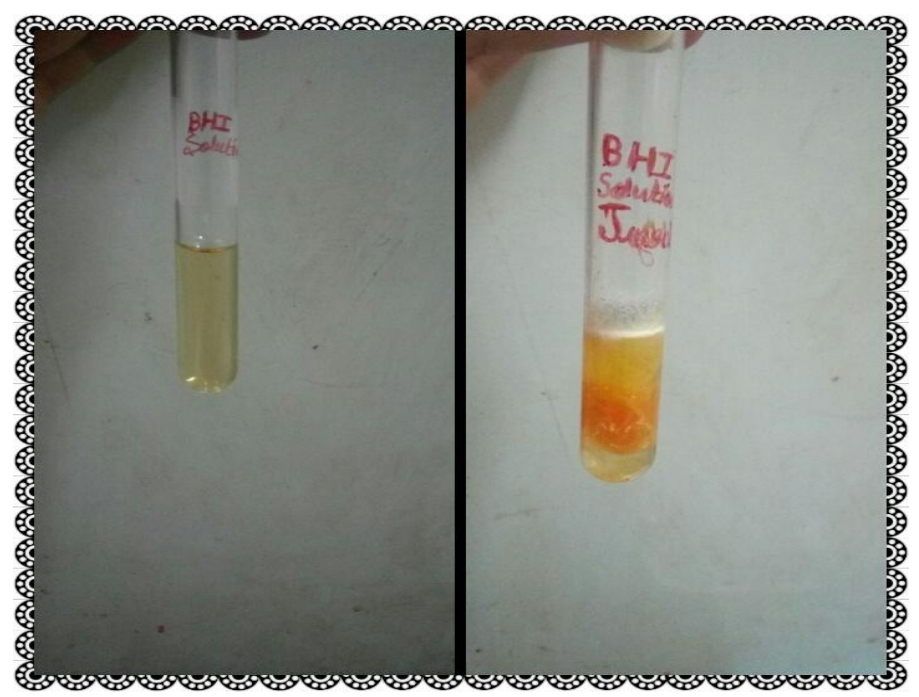

Fig.2 Microbial growth on nutrient agar, Mac-Conkey, SDA Isolation and characterization of Bacterial and Fungal colonies
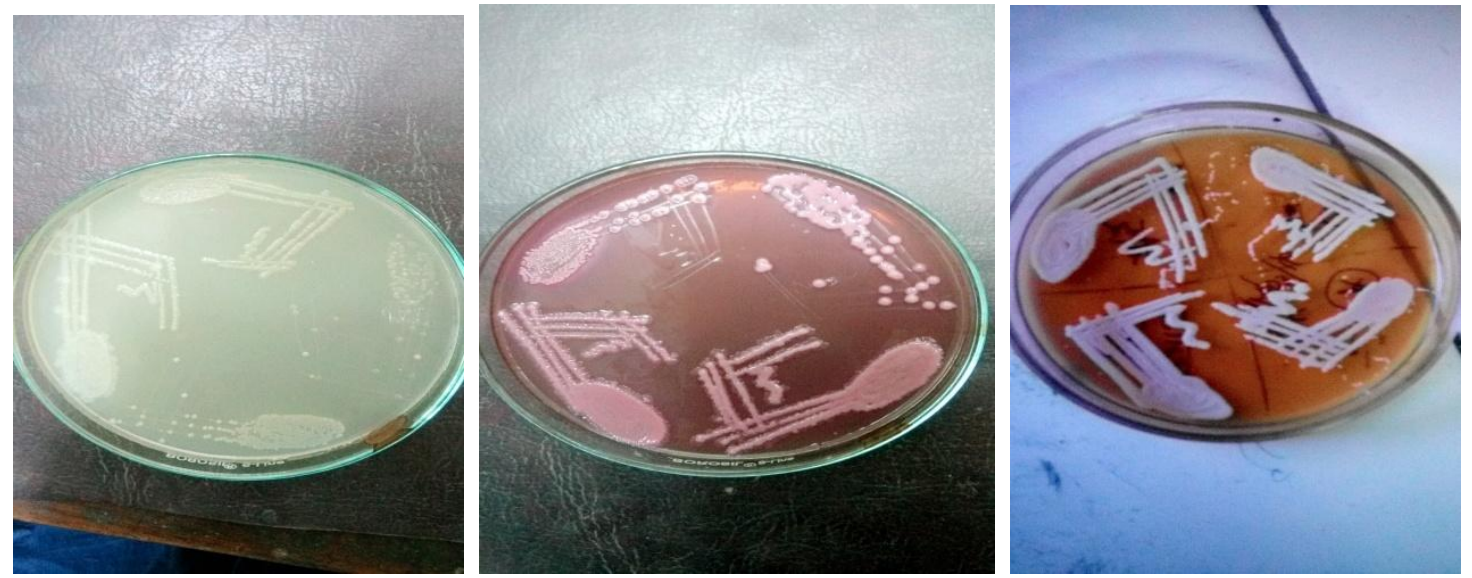

Fig.3 Antibacterial and Antifungal sensitivity pattern
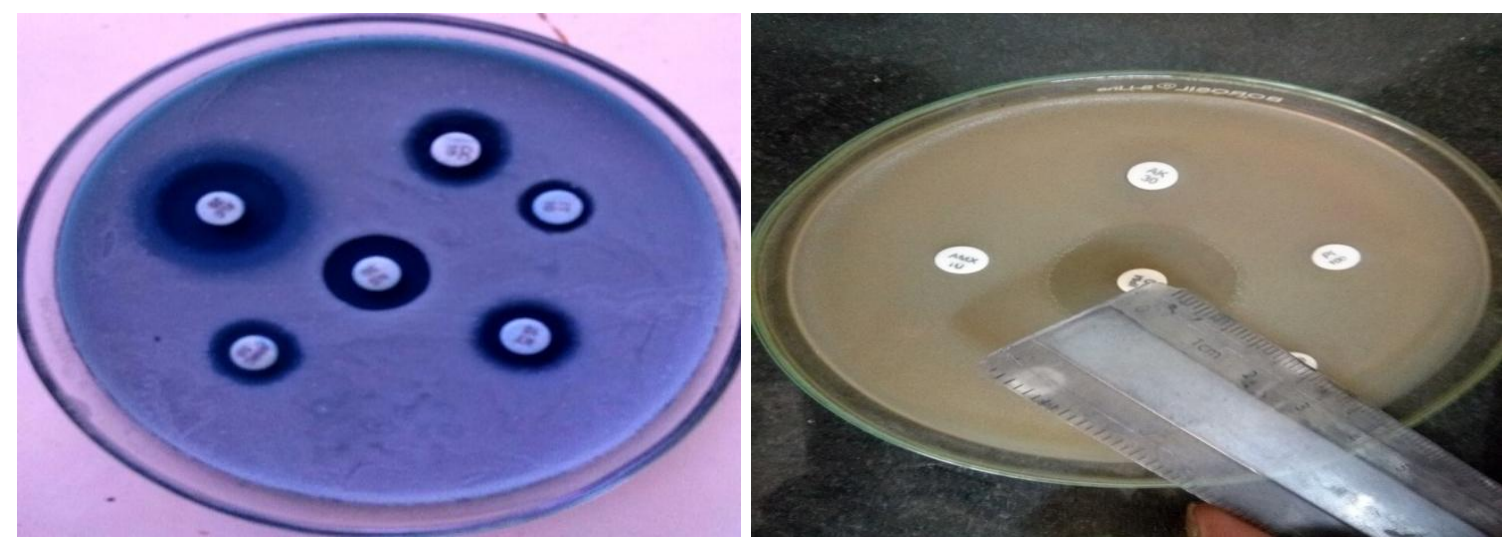

Table.3 GNB Candida species found in fruits and vegetables 


\begin{tabular}{|l|c|c|}
\hline Species in Perti plate & Total sample & \% \\
\hline GNB & 7 & $63.63 \%$ \\
\hline CANDIDA & 2 & $18.18 \%$ \\
\hline RHIZOPUS & 1 & $9.09 \%$ \\
\hline MUCOR & 1 & $9.09 \%$ \\
\hline
\end{tabular}

Table.4 Antibiotic sensitivity test in gram negative Bacillus

\begin{tabular}{|l|c|l|}
\hline \multicolumn{1}{|c|}{ Anti microbial agent } & Sensitivity in sample & \multicolumn{1}{c|}{$\%$} \\
\hline Amikacin & 4 & $50 \%$ \\
\hline Amoxycillin & 3 & $37.5 \%$ \\
\hline Piperacillin & 5 & $62.5 \%$ \\
\hline Ceftriaxone & 4 & $50 \%$ \\
\hline Ampicillin & 2 & $25 \%$ \\
\hline Imipenem & 8 & $100 \%$ \\
\hline
\end{tabular}

Table.5 Antifungal sensitivity test in Candida species, Rhizopus and Mucor

\begin{tabular}{|l|c|c|}
\hline & Sensitivity in Sample & $\%$ \\
\hline Nystatin & 2 & $50 \%$ \\
\hline Clotrimazole & 4 & $100 \%$ \\
\hline Itraconazole & 1 & $25 \%$ \\
\hline Ketoconazole & 2 & $50 \%$ \\
\hline Miconazole & 1 & $25 \%$ \\
\hline Fluconazole & 2 & $50 \%$ \\
\hline
\end{tabular}

Table.4 Bacterial and fungal results in collecting fruits and vegetable samples

\begin{tabular}{|l|l|l|l|}
\hline S. No. & \multicolumn{1}{|c|}{ Sample Name } & \multicolumn{1}{|c|}{ Microscopy } & \multicolumn{1}{|c|}{$\begin{array}{c}\text { Bacterial and Fungal } \\
\text { Organism }\end{array}$} \\
\hline $\mathbf{1}$ & Ananas comosus & Yeast bodies & Candida Species \\
\hline $\mathbf{2}$ & Solanum tuberosum & Rhizopus & Rhizopus \\
\hline $\mathbf{3}$ & Carica papaya & Mucor & Mucor \\
\hline $\mathbf{4}$ & Daucus carota & GNB & Klebsiella \\
\hline $\mathbf{5}$ & Musa paradisiaca $L$. & GNB & Klebsiella \\
\hline $\mathbf{6}$ & Manilkara zapota & GNB & Klebsiella \\
\hline $\mathbf{7}$ & Solanum Lycopersicon & GNB & Pseudomonas \\
\hline $\mathbf{8}$ & Vitisvinifera L. & GNB and Yeast bodies & Klebsiella and Candida Species \\
\hline $\mathbf{9}$ & Punica granatum & GNB & E. coli \\
\hline $\mathbf{1 0}$ & Malus domestica & GNB & E. coli \\
\hline
\end{tabular}




\section{References}

Amoa, I. O., Adebisi-Adelani, O., OlajideTaiwo, F. B. Adeoye, I. B. Bamimore, K.M and Olabode, I. 2011. Economic analysis of pineapple marketing in Edo and Delta States Nigeria. Libyan Agric.Red.Cen.J.Int1.2(5):205-208

Ewekye, 2013. Studies on post harvest deterioration some fruits and vegetables in selected market in Lagos state, Nigeria.

Jeanelle Boyer 2004. Nutrition Journal. 2004 3:5. Apple Phytochemicals and there health benefits.

Mahale,D.P., Ranjana,G.K.,and Varsha,K.V.(2008).Microbiological Analysis of street vended Fruit juices from Mumbai city India. Internal Journal of Food Safety. 10:31-34

Morton J F (1987). Pomegranate, Punicagranatum L.".Fruits of warm climate.Purdue New Crops Profile. PP.352-5. Retrieved 2012-06-14.

Omafuvbe,B. O. and Enyioha, L.C. (2011). Phenotypic Identification and technological properties lactic acid bacteria isolated from selected commercial Nigerian bottled yoghurt. African Journal of Food Science 5(6):340-348.

Snowdon, A.L.(1990).Atlas of Post harvest disease and Disorder of Fruit and vegetables . General Scientific Journal. 44:40-45

\section{How to cite this article:}

Khatri, P.K. and Sonali Sharma. 2018. Microbial Examination for Spoil Fruits and Vegetables and its Isolation, Identification, and Antimicrobial Sensitivity Pattern. Int.J.Curr.Microbiol.App.Sci. 7(12): 2671-2679. doi: https://doi.org/10.20546/ijcmas.2018.712.303 